\title{
Avaliação da viabilidade econômica da utilização de concreto de alto desempenho e lajes planas protendidas em edifício residencial estudo de caso
}

\section{Economic viability evaluation of the use of high performance concrete and prestressed flat slabs in a residential building: a case study}

\author{
Sérgio Henrique Pialarissi Cavalaro'; Gilberto Carbonari²
}

\section{Resumo}

O concreto de alto desempenho é utilizado internacionalmente como material de construção e tem vantagens sobre o aço. A situação brasileira, apesar de alguns esporádicos exemplos positivos, é diversa e ainda cheia de vácuos práticos e projetuais a serem preenchidos. O presente trabalho tem como objetivo avaliar, por meio de um estudo de caso, a viabilidade econômica da utilização de concreto de alto desempenho em uma edificação. O procedimento adotado passa pelo dimensionamento integral (inclusive de fundações) de dois edifícios, um com estrutura convencional e outro com concreto de alto desempenho. Só então se realizaram os levantamentos de custo e estimativa dos resultados econômicos diretos e indiretos. Por fim, as conclusões obtidas mostram-se como rica fonte de informações além de servirem de ponto norteador e incentivo tanto para o emprego do concreto de alto desempenho como para realização de mais estudos na mesma linha.

Palavras-chave: Concreto de alto desempenho. Viabilidade econômica. Estudo de caso.

\begin{abstract}
The high performance concrete is recognized and successfully used internationally as a possible substitute for the steel as a construction material. The Brazilian situation, despite a few sporadic good examples, is different and full of practical and project gaps. Therefore, the purpose of this research is to evaluate the economic viability of the use of high performance concrete in a building. The adopted procedure goes through the full structural project (including foundations) of two buildings, one of them with conventional structure and the other with high performance concrete. Not till then, it was possible to determine costs and an estimate of direct and indirect economic results. Finally, the conclusions obtained are seen as an important source of information besides being a guiding aspect not only for the use of high performance concrete, but also for the accomplishment of more studies about it.
\end{abstract}

Key words: High performance concrete. Economic viability. Case study.

\footnotetext{
${ }^{1}$ Aluno de graduação em Engenharia. Universidade Estadual de Londrina. E-mail: sergiohpc @ pop.com.br.

${ }^{2}$ Professor Doutor. Departamento de Estruturas. Centro de Tecnologia e Urbanismo. Universidade de Londrina

E-mail: carbonar@uel.br.
} 


\section{Introdução}

Tem-se observado, nas ultimas décadas, um acentuado desenvolvimento das ciências dos materiais, técnicas e tecnologias aplicadas à construção civil. Como resultado deste processo é notória a crescente gama de produtos e técnicas disponíveis que se mostram alternativas ao “convencional". Entretanto, a implementação e aplicação de tais inovações têm sido gradual e pautada por fases como familiarização, estudo de viabilidade e experimentação.

Neste contexto, não é incomum o aparecimento de paradigmas que proliferam inadvertidamente pelo meio técnico, embora boa parte deles seja fruto de avaliações equivocadas, incompletas ou imprecisas da aplicação das referidas inovações.

$\mathrm{Na}$ verdade, o campo da construção civil mostra-se extremamente amplo e complexo, com um grande número de atividades interdependentes. Por consequiência, torna-se também complexo qualquer estudo de viabilidade, uma vez que as alterações, por menores que sejam, causam desdobramentos sequienciais em todo processo produtivo. Assim, ao se implantar alguma inovação, esta proporciona resultados que podem ser classificadas como diretos ou indiretos.

Os resultados diretos são observados na própria atividade na qual foi introduzida a alteração e, em função deste fato, são geralmente de mais fácil quantificação. Já os resultados indiretos são aqueles que se manifestam em outros setores nos quais não foi introduzida a alteração, e caracterizam-se pela mais difícil avaliação e quantificação. Cabe ressaltar que ambas as classificações podem apresentar-se de forma positiva ou negativa e o resultado geral representa a somatória dos resultados diretos e indiretos ao longo do tempo.

De fato, decorre desse fato grande parte das polêmicas quanto à introdução de inovações, pois, boa parte das mesmas apresenta resultados econômicos diretos negativos. Contudo, dada a complexidade exigida, dificilmente é feito levantamento preciso dos resultados econômicos indiretos. Por conseqüência, o resultado final é determinado basicamente pelo primeiro.

Tome-se, como exemplo, o foco deste estudo que trata da avaliação de viabilidade econômica da utilização de concreto de alto desempenho (CAD) e laje plana protendida maciça (LPPM), em uma edificação.

O procedimento correto a ser adotado passaria pelo dimensionamento em separado de dois edifícios, um deles com estrutura convencional e o segundo com CAD e LPPM. Só então, se poderia realizar os levantamentos de custo e estimativa dos resultados econômicos diretos e indiretos.

Como se pode notar, seria um procedimento que, além de multidisciplinare intricado, demandaria bastantes estudos, pois é grande o volume de trabalho a ser efetuado. Ainda mesmo, sem se considerar aspectos técnicos.

Portanto, não são raras avaliações simplistas sobre a aplicação do CAD considerando uma gama de variáveis extremamente limitadas e predominantemente relativas ao custo direto do mesmo - diga-se de passagem - consideravelmente maior que o do concreto convencional.

Mas até que ponto a parcialidade quase inconsciente auferida costumeiramente ao assunto pode influenciar na análise final do profissional? $\mathrm{Ou}$ ainda, está o profissional sendo criterioso o suficiente e se baseando em aspectos minimamente racionais?

De pronto, não há como responder com certeza sob pena de incorrer no mesmo equívoco que se pretende avaliar. Antes, deve-se ajustar o método e o modelo adotado partindo-se de considerações menos abrangentes para a mais global.

Eis que só então o juízo da viabilidade econômica da utilização do sistema não convencional (NC) supracitado será medido efetivamente e as eventuais aproximações advindas de considerações mais simplistas poderão ser claramente apreciadas ou desprezadas. 


\section{Justificativa}

OCAD já se encontra bem difundido em países mais desenvolvidos como uma alternativa viável ao concreto convencional.

A realidade brasileira é totalmente diversa. Em menos de $3 \%$ das obras executadas se emprega aquele material. A despeito disso, as poucas experiências nacionais têm-se mostrado positivas. (ROCHA, 1997)

Especialistas defendem que, com a racional utilização do CAD, é possível obter economia de até $2 \%$ no valor total da estrutura, sem considerar alguns benefícios indiretos como aumento da área útil, diminuição do gastos com fundações, dentre outros. Entretanto, ao longo de toda a pesquisa realizada, não foram identificados trabalhos com a amplitude aqui proposta.

Os referidos trabalhos se limitam geralmente à análise de apenas um pavimento da estrutura e, em boa parte, ignoram alguns resultados indiretos. Por isso, a análise de eficiência do CAD torna-se extremamente parcial.

Perante a escassez de bibliografia acerca do assunto, torna-se interessante a realização de um estudo de viabilidade econômica amplo e equilibrado a respeito da utilização de CAD e LPPM em uma edificação.

Com isso, pretende-se dar significativa contribuição, principalmente para desmistificar questões sobre o desempenho econômico daquele material.

Há, sem dúvida aí, uma grande lacuna a ser preenchida, pois somente com um levantamento global será possível obter uma análise comparativa precisa. Considera-se que unicamente quando todos os pontos sobre o CAD forem esclarecidos, o material será aceito e empregado.

\section{Objetivo}

Foi objetivo deste trabalho realizar um estudo de viabilidade econômica da utilização do sistema composto por CAD e LPPM em um edifício residencial.

\section{Método}

Pela própria intitulação do presente trabalho, abstrai-se facilmente um estudo por meio da comparação de duas situações distintas, com uma delas relativamente inexplorada.

Tendo em vista que a obviedade na maioria dos casos se traduz em eficácia, foi exatamente este o método adotado. A simples comparação da evolução dos indicadores econômicos pertinentes a duas edificações: uma com estrutura convencional (C) e outra com utilização de CAD e LPPM. Para realizar a comparação das características econômicas das duas edificações, será preciso adquirir primeiro a matéria-prima para tal, ou seja, dimensioná-las.

É neste ponto, profundamente interligado à precisão da análise final, que se deve fazer o maior número de considerações e despender-se maior atenção. Assim, sabendo-se da extensão e grande número de estudos a serem desenvolvidos, por questão de eficiência e qualidade, o método foi subdividido nas seguintes etapas:

- Escolha da edificação em estrutura C;

- Levantamento de cargas e carregamentos;

- Dimensionamento e desenho da estrutura C;

- Lançamento, dimensionamento e desenho da estrutura em CAD e LPPM;

- Produção do orçamento da estrutura C e NC;

- Levantamento de indicadores econômicos da estrutura $\mathrm{C}$ e NC;

- Análise comparativa dos resultados e considerações finais sobre a viabilidade econômica.

\section{Escolha da edificação em estrutura $C$}

O primeiro passo foi a escolha de uma edificação real, preferencialmente já executada, e com possibilidade de obtenção dos projetos estruturais e arquivos eletrônicos de dimensionamento. Como critérios para escolha exigia-se também que a edificação tivesse mais de 10 pavimentos, uma boa distribuição em planta e pelo menos um pavimento de garagens. 
Nesta etapa se encontrou boa parte dos entraves à realização do estudo. Existia enorme dificuldade em se obter uma empresa de execução e, mais ainda, uma empresa de cálculo estrutural, que se disponibilizassem a fornecer as plantas necessárias e o arquivo eletrônico de dimensionamento. Após algum tempo de procura conseguiu-se encontrar empresas prontas a colaborar, muito embora se tivesse de abrir mão de alguns critérios para a escolha da edificação.

Cabe ressaltar que o arquivo eletrônico de dimensionamento seria essencial para diminuir o volume de trabalho. Com ele, ter-se-iam as cargas e critérios de projetos considerados no dimensionamento, e eles limitariam as atividades apenas ao dimensionamento da estrutura NC.

Tendo em vista que em nenhuma das hipóteses foi possível a obtenção de tais arquivos tornou-se obrigatória a realização do dimensionamento e projeto estrutural de ambas a estruturas, pois apenas dessa forma se teria certeza da utilização das mesmas ações e critérios de projetos nos dois dimensionamentos.

Assim, o projeto estrutural preexistente serviu como modelo de lançamento estrutural e como base de comparação para o dimensionamento obtido para a estrutura $\mathrm{C}$.

\section{Levantamento de cargas e carregamentos}

Partiu-se do pressuposto de que para uma comparação precisa dos resultados das duas edificações em estudo seria indispensável considerar as mesmas ações em ambas. Desse modo, o levantamento das cargas permanentes e sobrecargas de utilização foi realizado em função do projeto arquitetônico através do estabelecido na NBR 6120.

As ações de vento foram obtidas em conformidade com a NBR 6123, e foram aplicadas na forma de quatro casos de carregamento nas duas direções críticas apontadas pelo projetista estrutural da estrutura C. Fizeram-se as combinações dos carregamentos conforme preconizam as normas NBR 6118 e NBR 8681.

\section{Dimensionamento e desenho da estrutura $C$}

Outro ponto importante na igualdade de condições dos projetos foi a uniformização da maioria dos critérios de dimensionamento. Optouse, em vias de agilização do processo, pela utilização de ferramental computacional de cálculo estrutural. Este, por questões de coerência e disponibilidade para uso, foi o mesmo utilizado pelo projetista estrutural no dimensionamento da estrutura $\mathrm{C}$, embora de versão mais recente - o TQS.

No referido programa, fez-se o lançamento dos carregamentos levantados e, também, da estrutura C conforme a havia concebido seu projetista responsável. Através deste procedimento, queriase obter armadura para lajes, vigas e pilares, tão próximas quanto possível às apresentadas no projeto estrutural. Para tanto, se buscou extrair dos projetos alguns critérios considerados no dimensionamento da estrutura $\mathrm{C}$, e esses critérios guiaram os trabalhos.

O projeto estrutural feito pelo projetista data anteriormente ao inicio de vigência da NBR 6618/03. Ademais, o programa computacional adotado também se encontrava calibrado para a antiga NB-1.

Como a normalização vigente (NBR 6118/03) conserva muitos aspectos da anterior (NB-1), foi possível na grande maioria dos casos atender à primeira. Nos casos em que as normas divergiam, na medida do possível, as alterações foram feitas manual e posteriormente ao dimensionamento de forma a atender a NBR 6118/03. A opção pela utilização de NBR 6118/03 partiu do pressuposto de traduzir com boa exatidão as condições de dimensionamento atualmente utilizadas em projetos estruturais. 


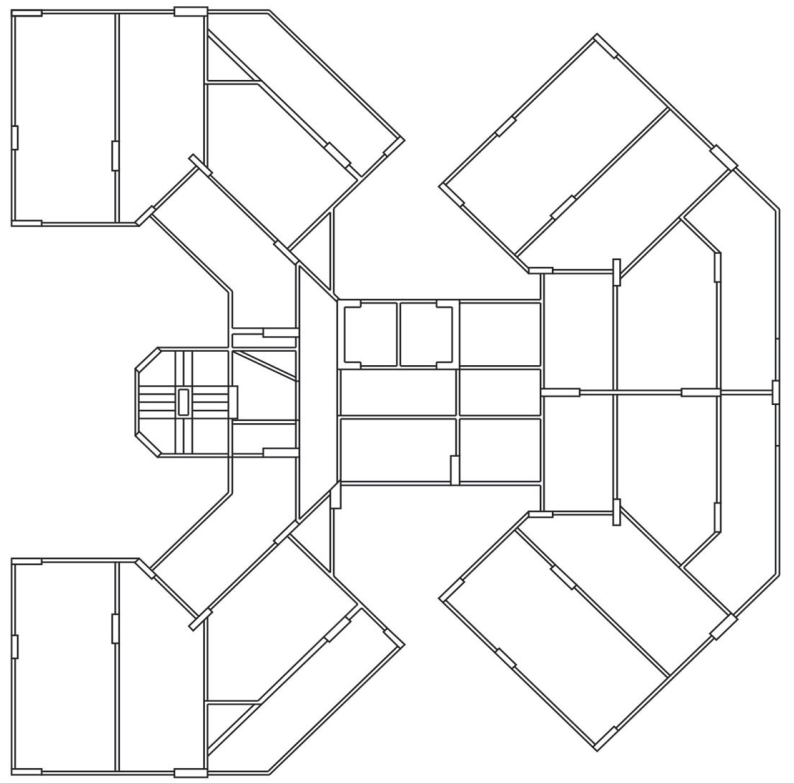

Figura 1. Planta estrutural esquemática da edificação C

Para obtenção dos esforços de cálculo advindos de cargas permanentes e sobrecargas de utilização, utilizou-se o modelo de grelha de vigas e lajes descarregando em pilares conforme disponibiliza o programa TQS.

Já os esforços devidos ao vento, foram obtidos tanto no programa SAP como no programa TQS com pórtico espacial de pilares e vigas. Esse procedimento buscou assegurar a representatividade dos modelos estruturais aplicados uma vez que seus esforços resultantes seriam utilizados no dimensionamento de vigas e pilares.

O dimensionamento, detalhamento e desenho da estrutura $\mathrm{C}$ foi realizado no programa TQS.

\section{Lançamento, dimensionamento e desenho da estrutura em CAD e LPPM}

Na concepção de uma estrutura que incorpore o CAD, atentou-se para a escolha criteriosa do sistema estrutural adotado. OCAD tem como ponto de realce na realização do projeto estrutural sua elevada resistência além de maiores custos diretos. Dessa forma, os resultados econômicos proporcionados por aquele material serão melhores quando da sua aplicação em pontos onde sua propriedade de destaque seja mais completamente aproveitada.

Partindo-se disso, optou-se pela utilização do CAD prioritariamente nos elementos estruturais mais solicitados quanto à compressão, isto é, nos pilares. Ademais, o sistema estrutural organizado em laje viga-pilar de concreto armado com pilares em $\mathrm{CAD}$ não seria o mais adequado. Sabe-se que no referido sistema a concentração das cargas nos pilares é consideravelmente limitada pelos vãos de vigas e lajes. Algo que se traduz em restrição no potencial de redução do número de pilares.

Uma alternativa estudada foi a utilização de CAD também em vigas e lajes, o que aumentaria consideravelmente os vãos vencidos e, assim, as cargas nos pilares. No entanto, tal consideração foi evitada, uma vez que indutivamente acarretaria um subaproveitamento da capacidade resistente do material diminuindo a eficiência de utilização do mesmo sem trazer benefícios na mesma proporção.

Outra possibilidade contemplada tratava da escolha de um sistema estrutural com maior flexibilidade de locação dos pilares, capaz de vencer maiores vãos e com capacidade de aproveitamento mais efetivo das características próprias daquele concreto. Escolheu-se para tanto o sistema composto por pilares em CAD dando suporte a LPPM. Neste, em função da protensão aplicada às lajes, seria facilmente possível, mesmo sem empregar o CAD, vencer vãos em torno de $10 \mathrm{~m}$.

Feito o lançamento da estrutura NC, seu dimensionamento foi dividido em duas fases: dimensionamento das LPPM em programa específico e dimensionamento dos pilares na interface de pilares do programa TQS. A análise de esforços e dimensionamento das LPPM foi realizado somente para as cargas permanentes e sobrecargas de utilização através de interface específica do programa TQS. Já os pilares foram dimensionados para os esforços advindos tanto das cargas permanentes e sobrecargas de utilização quanto para a ação do vento e carga de protensão. Novamente adotou-se o procedimento de analisar 
os esforços devido ao efeito do vento nos programas SAP e TQS a fim de validar as condições de contorno.

Como já era esperado, em função da diminuição no número e secção transversal dos pilares, a ação do vento correspondeu à parcela predominante nos esforços solicitantes atuantes. Com isso, foi preciso criar uma estruturação interna à própria edificação específica para absorver boa parte das cargas de vento. Tudo feito mediante a introdução de um núcleo central de inércia composto por um único pilar que contorna os dutos de elevadores. Consequentemente, reduziu-se drasticamente o momento fletor e cortante de cálculo na base dos pilares que passaram a trabalhar de acordo com a intenção inicial - praticamente apenas a solicitações normais de compressão.

Fez-se o dimensionamento da LPPM mediante a normalização competente sobre o assunto, a NBR 7197.

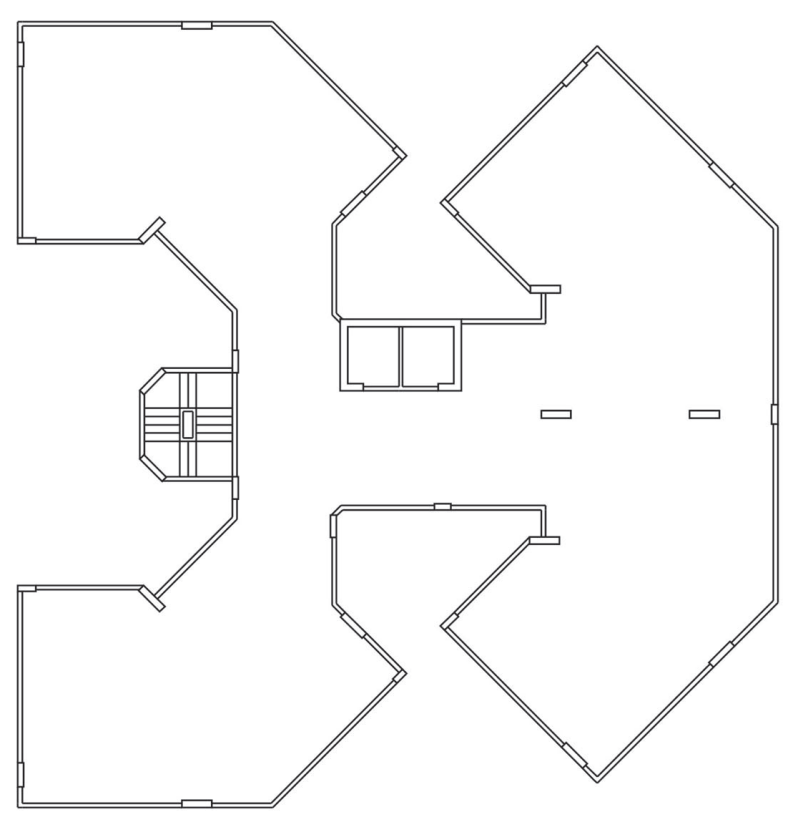

Figura 2. Planta estrutural esquemática da edificação NC

Aplicam-se aqui as mesmas considerações apresentadas no item anterior quanto a NBR 6618/ $03 \mathrm{e}$, ao longo do processo de dimensionamento, buscou-se manter as mesmas cargas e critérios de projeto utilizados no projeto da estrutura $\mathrm{C}$.
Produção dos cronogramas, orçamentos e fluxos de caixa da estrutura $C$ e NC

Com os projetos estruturais concluídos realizouse a composição dos orçamentos de ambas as estruturas e, paralelamente, determinaram-se os cronogramas, orçamentos e fluxos de caixa para as duas edificações. Boa parte dos valores adotados ao longo destes procedimentos foi obtida por consulta à empresa responsável pela execução da estrutura C.

Levantamento de indicadores econômicos da estrutura $C$ e $N C$

Após a produção de orçamentos, fez-se um levantamento dos indicadores econômicos destacando-se a taxa interna de retorno (TIR) e valor presente líquido (VPL). Para a obtenção destes índices foi necessária a fixação de um cenário econômico prevendo ritmo de vendas das unidades habitacionais, capacidade de poupança dos compradores, dentre outros parâmetros. Considerou-se ainda que no caso da edificação com CAD e LPPM, os benefícios advindos da utilização deste sistema, acabaram por agregar valor a cada unidade habitacional. Para ilustrar, vide o aumento da área útil comercializável em função da diminuição do número e redução das secções dos pilares.

Não foi possível, entretanto, levar em conta outros benefícios mais abstratos e de difícil quantificação. Cita-se, por ocasião da diminuição no número de pilares, o exemplo do aumento da flexibilidade do "layout" arquitetônico", que poderá reverter num diferencial e ponto positivo de comercialização, marketing e satisfação do cliente.

Análise comparativa dos resultados $e$ considerações finais sobre a viabilidade econômica

A partir do que se verificou nos indicadores econômicos e orçamentos das duas edificações, foi possível realizar uma análise comparativa e de viabilidade das mesmas. De início, buscou-se 
determinar os efeitos da mudança do sistema estrutural no processo de confecção da própria estrutura, ou seja, os resultados diretos. Em um segundo momento, por atividade, foi verificado o efeito causado pela alteração do sistema estrutural nos demais serviços executados na edificação, ou seja, os resultados indiretos. Ademais, fez-se uma análise de viabilidade econômica segundo os critérios da TIR e do VPL.

\section{Critério da TIR}

A TIR é a taxa que proporciona a somatória nula dos investimentos e retornos descontados por meio desta a uma mesma data. Trata-se da mínima taxa que garante a recuperação da quantidade investida. Para que o investimento seja interessante o valor obtido para a TIR tem de ser maior que a taxa mínima de atratividade (TMA) estabelecida pelos investidores. (GALESNE, 1999).

\section{Critério do VPL}

O VPL é a diferença entre os montantes de retorno e de investimento descontados por meio de uma dada taxa ao tempo presente do estudo. A taxa usualmente empregada é a TMA definida pelo investidor. Para que o empreendimento seja rentável o VPL deve apresentar valores positivos. Em empreendimentos nos quais haja mais de uma hipótese de aplicação com características distintas, aidentificação da mais viável economicamente é feita por comparação de seus VPL, e a mais indicada é a que apresentar maior valor.(GALESNE, 1999)

\section{Exposição e observações sobre os resultados econômicos}

Os resultados econômicos, ao lado de parâmetros técnicos, são usualmente as ferramentas principais para determinar a viabilidade de um empreendimento. Entretanto, a consideração única de indicadores globais tende a subjugar os meios que os originaram. Perde-se, assim, na justificativa dos resultados obtidos, e pior ainda, na possibilidade de otimização do processo projetual.

Sabe-se que a concepção e cálculo de um projeto estrutural exigem experiência e alto nível de conhecimento. Por isso, deve ser inata ao bom projetista a constante realimentação de seu sistema de trabalho com a avaliação das reais conseqüências de suas decisões. Com base nesse princípio, far-se-á, em seguida, uma análise comparativa particularizada por elemento estrutural.

\section{Fundações}

Inicialmente, era esperada grande economia no quesito fundações. Boa parte deste adviria do possível menor peso próprio da estrutura $\mathrm{NC}$ perante a estrutura $\mathrm{C}$. Esse procedimento, porém, não se confirmou, pois as dimensões adotadas para vigas e lajes da estrutura $C$ perfizeram a espessura média de $14,5 \mathrm{~cm}$. Esse valor já menor que o assumido no projeto da estrutura $\mathrm{NC}$, ou seja, o mínimo de $15,0 \mathrm{~cm}$ estabelecido em norma para lajes protendidas.

Por outro lado, o consumo adicional de concreto nas lajes foi contrabalanceado pelo menor consumo do mesmo nos pilares. Dessa forma, o peso próprio da estrutura $\mathrm{NC}$ praticamente equivaleu-se ao da estrutura $\mathrm{C}$.

Mesmo assim, observa-se na tabela resumo abaixo uma leve economia, próxima de $3,1 \%$, para a estrutura $\mathrm{C}$.

Tabela 1. Comparativo de gastos com fundações

\begin{tabular}{c|cccccc} 
& \multicolumn{3}{c}{$\begin{array}{c}\text { Estrutura Convencional } \\
\text { (em reais) }\end{array}$} & \multicolumn{3}{c}{ Estrutura Não Convencional } \\
\cline { 2 - 7 } & Mat & MO & Subtotal & Mat & MO & Subtotal \\
Fundações & 109.284 & 49.814 & 159.098 & 104.283 & 49.960 & 154.243 \\
\hline
\end{tabular}


Fica claro que isso ocorreu majoritariamente em função da diminuição no número de tubulões e dos gastos com escavação e execução dos fustes. Tal efeito foi motivado pela diminuição do número de pilares. Em seguida deveu-se ainda à necessidade imposta pelo perfil geotécnico em se alcançar a cota de $15 \mathrm{~m}$ de profundidade para atingir solo minimamente resistente.

\section{Pilares}

A introdução da laje protendida permitiu o aumento considerável do vão entre pilares. Ademais, a utilização de concretos com resistência à compressão mais elevada nos andares inferiores possibilitou que as maiorias das secções transversais ficassem abaixo do limite de $20 \mathrm{~cm} \mathrm{X} 100 \mathrm{~cm}$. Por conseguinte, observou-se, para os pilares, uma economia próxima de $30,0 \%$ no volume de concreto da estrutura $\mathrm{NC}$ perante a $\mathrm{C}$.

Sabia-se que tamanha vantagem diminuiria drasticamente ao levar em conta o custo do concreto.

Não se esperava, entretanto, que a pesar de perder em magnitude aquela ainda mantivesse sua propriedade.
Explicando melhor, mesmo com o custo adicional da utilização de resistências de $30 \mathrm{MPa}, 45 \mathrm{MPa}$ e $60 \mathrm{MPa}$, houve a redução de $13,5 \%$ nos gastos com concreto, o que foi devido sobretudo à modificação do sistema estrutural das lajes e, principalmente, pela utilização racionalizado do concreto.

Outro aspecto que contribui para este resultado são as melhorias tecnológicas e aperfeiçoamentos introduzidos na produção de concretos de mais elevadas resistências. Com isso, observa-se nos últimos anos, uma aproximação relativa entre os preços do concreto $\mathrm{C}$ e o $\mathrm{CAD}$.

No que concerne ao aço, observou-se um aumento de 9,0\% da taxa média de armadura para os pilares da estrutura NC. Porém, ao considerar a redução de $30,0 \%$ na secção transversal dos mesmos constata-se economia de 8,2 no consumo de aço, o que equivale a uma redução de $8,4 \%$ nos gastos com este material.

Foi nas áreas de formas onde se verificou maior diferença percentual entre a estrutura $\mathrm{NC}$ e a $\mathrm{C}$ $32,6 \%$ em prol da primeira. Portanto, houve economia de $22,6 \%$ nos gastos com materiais para formas.

No cômputo geral para pilares, com todos os materiais supracitados e mão de obra inclusa, os gastos com a estrutura $\mathrm{NC}$ foi $17,7 \%$ menor que o da estrutura $\mathrm{C}$.

Tabela 2. Comparativo de gastos com pilares

\begin{tabular}{|c|c|c|c|c|c|c|}
\hline & \multicolumn{6}{|c|}{ Pilares (custos em reais) } \\
\hline & \multicolumn{3}{|c|}{ Estrutura Convencional } & \multicolumn{3}{|c|}{ Estrutura Não Convencional } \\
\hline & Total Mat. & Total MO & Subtotal & Total Mat. & Total MO & Subtotal \\
\hline Concreto & 112.120 & 31.518 & 143.638 & 96.999 & 22.373 & 119.372 \\
\hline Armaduras & 227.264 & 119.842 & 347.106 & 208.087 & 109.945 & 318.032 \\
\hline Formas & 53.132 & 188.043 & 241.175 & 35.770 & 129.763 & 165.533 \\
\hline Total & 392.515 & 339.404 & 731.919 & 340.856 & 262.081 & 602.937 \\
\hline
\end{tabular}

Vigas

As vigas seguiram o mesmo comportamento dos pilares, e apresentaram para a estrutura NC economia para gastos com materiais em concreto, armadura e forma. Esse fato ocorreu porque na estrutura NC foram empregadas apenas vigas perimetrais com a finalidade de auxiliar na ancoragem de protensão. Assim, houve grande diminuição no comprimento linear total por andar acompanhado de um pequeno aumento da resistência e da área da secção transversal das vigas 
Tabela 3. Comparativo de gastos com vigas

Vigas (custos em reais)

\begin{tabular}{ccccccc}
\cline { 3 - 6 } & \multicolumn{3}{c}{ Estrutura Convencional } & \multicolumn{3}{c}{ Estrutura Não Convencional } \\
\cline { 3 - 6 } & Total Mat. & Total MO & Subtotal & Total Mat. & Total MO & Subtotal \\
\cline { 1 - 6 } Concreto & 59.375 & 17.388 & 76.763 & 39.236 & 9.688 & 48.923 \\
Armaduras & 120.802 & 61.731 & 182.532 & 42.100 & 20.620 & 62.720 \\
Formas & 41.585 & 153.925 & 195.510 & 21.715 & 87.798 & 109.513 \\
$\quad$ Total & 221.762 & 233.043 & 454.805 & 103.050 & 118.106 & 221.155
\end{tabular}

No compute geral para vigas, considerando material e mão de obra, houve economia de $51,3 \%$ da estrutura NC perante a estrutura C.

Cabe ressaltar aqui uma diferença para com o item anterior sobre pilares. Naquele, a economia observada deveu-se em grande parte ao aumento da capacidade resistente da secção transversal.

Já para as vigas, os resultados positivos têm bem pequena relação com a melhoria de suas propriedades pela utilização de concreto mais resistente. Foi, na verdade, produto da diminuição do comprimento linear total possibilitado pelo sistema composto por laje protendida e pilares em CAD.

Lajes

Foi nas lajes que se identificou maior o problema quanto à otimização econômica dos resultados obtidos para a estrutura NC. Primeiro pela necessidade de se realizar a protensão que representa substancialmente um gasto adicional. Segundo, porque seria preciso empregar concreto com resistência característica mínima prevista em norma de 30MPa. A isso se acrescenta a impossibilidade de executar uma laje protendida com espessura inferior a $15 \mathrm{~cm}$ (não somente devido a prescrições normativas, mas também pela dificuldade em distribuir os cabos de protensão satisfatoriamente em elementos de menores espessuras).

Fica claro o resultado da comparação da estrutura NC, sujeita às limitações contextuais expostas, com a estrutura $\mathrm{C}$, cujas lajes tinham espessura de $10 \mathrm{~cm}$. O volume de concreto consumido na estrutura $\mathrm{NC}$ foi $55,4 \%$ maior que o da estrutura $\mathrm{C}$. Contudo, os gastos em concreto superaram este valor sendo $74,5 \%$ maior na estrutura NC.

Tabela 4. Comparativo de gastos com lajes

\begin{tabular}{ccccccc}
\cline { 3 - 6 } & \multicolumn{6}{c}{ Lajes (custos em reais) } \\
\cline { 2 - 7 } & \multicolumn{4}{c}{ Estrutura Convencional } & \multicolumn{3}{c}{ Estrutura Não Convencional } \\
\cline { 2 - 7 } & Total Mat. & Total MO & Subtotal & Total Mat. & Total MO & Subtotal \\
Concreto & 134.883 & 48.265 & 183.148 & 248.659 & 70.162 & 318.821 \\
Armaduras & 95.889 & 41.379 & 137.268 & 369.360 & 105.937 & 475.297 \\
Formas & 59.936 & 208.820 & 268.756 & 62.169 & 208.582 & 270.751 \\
Total & 290.708 & 298.464 & 589.172 & 680.188 & 384.682 & 1.064 .869
\end{tabular}


Nos gastos, tanto com a armadura passiva quanto a ativa, novamente a estrutura NC teve maior custo, próximo de 246,2\% acima da estrutura C. Em um grau menor, essa realidade se repetiria, mesmo que se comparasse apenas a armadura passiva de ambas as edificações. Nota-se que no cômputo geral, considerando tanto material quanto mão de obra, houve gasto adicional de $81,0 \%$ na estrutura NC comparativamente à estrutura $\mathrm{C}$.

Apesar do cenário aparentemente negativo, deixar-se influenciar única e definitivamente pelos valores expostos neste item seria uma grande falha de análise global do empreendimento. Não se pode esquecer: existem outros benefícios advindos do emprego deste elemento estrutural os quais não se manifestam simplesmente no seu custo direto. Veja-se o obtido no caso das vigas dentre outros exemplos que serão explicitados mais adiante.

\section{Estrutura como um todo}

O quadro abaixo traz a composição de gastos para ambas as estruturas estudadas.

Tabela 5. Comparativo dos gastos como um todo em ambas as estruturas

\begin{tabular}{c|cccccc} 
& \multicolumn{3}{c}{$\begin{array}{c}\text { Estrutura Convencional } \\
\text { (em reais) }\end{array}$} & \multicolumn{3}{c}{$\begin{array}{c}\text { Estrutura Não Convencional } \\
\text { (em reais) }\end{array}$} \\
\cline { 2 - 7 } & MO & Mat & Subtotal & MO & Mat & Subtotal \\
\hline Fundações & 49.814 & 109.284 & 159.098 & 49.960 & 104.283 & 154.243 \\
Concreto* & 97.168 & 306.377 & 403.545 & 102.229 & 384.894 & 487.122 \\
Armadura* & 222.952 & 443.954 & 666.906 & 176.384 & 679.660 & 856.045 \\
Forma* & 550.791 & 154.653 & 705.444 & 426.142 & 119.654 & 545.796 \\
Total & 920.725 & 1.014 .269 & 1.934 .994 & 754.715 & 1.288 .491 & 2.043 .206
\end{tabular}

Pelos dados observa-se que, em valores absolutos, a estrutura NC teve custo mais elevado que a $\mathrm{C}$.

Pesou para tal resultado o montante despendido com material, principalmente no quesito armadura. Assim, os gastos totais com material foram 27,3\% maiores na estrutura NC. Em contrapartida, pelas técnicas utilizadas, há redução na demanda de capital humano na estrutura $\mathrm{NC}$ ocorrendo economia de $18,0 \%$ com o mesmo.

Essas verificações têm importantes conseqüências ao longo da execução da obra. Devido às técnicas empregadas na estrutura NC há necessidade de maior planejamento e racionalização. Ademais, este processo é facilitado, visto que há diminuição da dependência de capital humano na nova concepção estrutural. Tenha-se em mente que reconhecidamente no contexto atual, sistematizar e controlar a qualidade do fator humano é bem mais difícil que a do fator material.

Verificando a proporção de gastos da estrutura $\mathrm{C}$, forma e armaduras foram os itens mais representativos correspondendo a $71 \%$ dos gastos totais. Apenas em terceiro lugar, com $21 \%$ dos gastos totais, aparecem as atividades de concretagem. Na estrutura NC, ganharam em representatividade os gastos com armadura, impulsionada pela armadura ativa, e os gastos com concreto, pela utilização de maiores resistências.

\section{Análise da Viabilidade Econômica}

Já de antemão deve ficar explícito que a viabilidade é algo relativo. Depende do ponto de vista adotado e de como se observa o cenário que envolve a aquilo estudado. 
O próprio cenário a ser considerado é extremamente incerto e influenciado por variáveis de difícil entendimento. Tal questão é relevante a ponto de fazer emergir a dúvida: até que nível de detalhamento é plausível simular a possível realidade?

Oengenheiro tem de realizar escolhas como esta com grande freqüência. Em diversas situações, quando há alternativas contrastantes, tem-se de optar com base racional àquilo entendido como mais viável. Indubitavelmente neste aspecto, a precisão do modelo adotado para tomada de decisão qualificará a eficiência do autor da análise.

Assim, para ilustrar a importância do supracitado, o presente estudo foi realizado de três maneiras distintas. Cada uma delas com pressupostos e níveis de detalhamentos diferentes. Buscou-se assim esclarecer os benefícios e malefícios de cada método.

Quanto ao ponto de vista adotado, optou-se pelo papel do empreendedor do ramo da construção civil. Faz-se aqui uma ressalva para a confusão que normalmente é feita entre o termo investidor e o termo empreendedor. Investidor é o indivíduo ou entidade que tem a posse do capital a ser investido, sendo de sua escolha a aplicação do mesmo. O empreendedor é o indivíduo ou entidade encarregado, através de suas atividades, de realizar a aplicação do capital em vias de obter o rendimento esperado pelo investidor. A remuneração do empreendedor geralmente se dá de forma pré-fixada ou sobre o rendimento adicional à atratividade mínima do investidor.

Independentemente da modalidade, será objetivo do empreendedor, considerando os riscos inerentes, maximizar o rendimento da aplicação: seja para aumentar a satisfação do investidor; seja para ampliar seus próprios recebimentos.

Apesar de muitos não enxergarem conotação tão direta com a profissão, o engenheiro é constantemente desafiado pelo mercado e pela crescente gama de suas atribuições a pensar como empreendedor. Trata-se de extremamente positivo na medida que o obriga a tentar prever comportamentos de mercado, estudar riscos e tentar diminuí-los. Antes disso, é ainda uma grande oportunidade de crescer e diferenciar-se profissionalmente.

\section{Análise comparativa direta dos orçamentos das estruturas}

\section{Modelo adotado}

Consiste em determinar as atividades realizadas ao longo da execução de ambas as estruturas. Para cada atividade, a partir de uma ficha de composição unitária, determina-se o quantitativo total de material e mão de obra. Realizou-se também pesquisa de mercado para levantamento dos preços de cada recurso e insumo empregado. Estes valores, combinados aos quantitativos, geraram o orçamento de cada estrutura. Por fim, realizou-se a comparação dos custos totais obtidos.

\section{Cenários e pressupostos adotados}

Como entrada de informação, temos os preços dos recursos e insumos empregados e as fichas de composição unitária de cada atividade. Os preços dos recursos e insumos foram obtidos através do banco de dados da empresa responsável pelo empreendimento, assim como, em revistas do meio da construção civil. A composição unitária das atividades foi obtida na TCPO da editora Pini. Ademais os valores considerados foram validados por responsável da empresa originalmente encarregado do empreendimento.

\section{Determinação dos orçamentos}

Os valores finais são os mesmos apresentados no item Considerações sobre os resultados. 


\section{Considerações sobre os resultados}

Pela simples comparação dos orçamentos, observa-se que a estrutura $\mathrm{NC}$ foi aproximadamente $5,7 \%$ mais cara que a estrutura C. Assim, caso pautássemos nossa decisão por esta análise, a estrutura $\mathrm{C}$ pareceria a mais indicada tendo em vista a economia proporcionada. Entretanto, não é difícil perceber que o modelo utilizado peca em diversos aspectos notáveis comprometendo a precisão da análise.

Deve-se considerar, porém, o cenário considerado, ou seja, o conjunto de preços de recursos e insumos, embora sujeito a variações relativamente previsíveis, é demasiadamente restrito.

Ademais, o foco dado ao estudo - limitado a custos diretos e à estrutura - impossibilita a consideração de benefícios indiretos de outras naturezas.

Outro complicador é o fato de a grandeza tempo não ser, em nenhum momento, incorporada à análise. Isso é inconcebível para um investimento de longo prazo de maturação. Como conseqüência disso, há a impossibilidade da consideração de qualquer tipo de risco inerente ao investimento.

\section{Análise comparativa direta dos orçamentos dos empreendimentos considerando o ganho na área}

\section{Modelo adotado}

O primeiro passo foi a estipulação de cronogramas executivos considerando as dependências e limitações de todas as atividade. A fim de manter a isonomia entre as duas edificações preferiu-se utilizar o princípio da execução tão rápida quanto possível.

Em função disso, os sistemas estruturais adotados apresentaram velocidades executivas distintas. Conseqüentemente, as atividades dependentes da execução da estrutura também sofreram alterações em sua velocidade.

Cabe mencionar que o encurtamento executivo da estrutura $\mathrm{NC}$ relativamente à $\mathrm{C}$ foi determinado com base nas características e limitações executivas de cada sistema estrutural. Obtiveram-se assim, para a estrutura $\mathrm{C}$ o limite máximo executivo de dois pavimentos por mês, e para a estrutura NC, três pavimentos por mês.

Com os cronogramas em mãos, realizou-se a composição dos orçamentos de ambas as edificações. Entraram também na composição dos mesmos, atividades como: revestimento interno, paisagismo, instalações hidráulicas, dentre outros.

O encurtamento do prazo executivo do empreendimento torna-se interessante na medida que diminui a importância consumida em despesas fixas (manutenção da instalação do canteiro de obra e rateio de despesas administrativas).

Adicionalmente foi considerado o ganho de receita advindo do aumento da área utilizável e da área útil na estrutura NC. Espera-se com isso demonstrar que a introdução de alguns fatores indiretos já é capaz de alterar significativamente a análise comparativa dos orçamentos.

Para compreenderem-se os procedimentos adotados neste item é preciso adentrar às tendências recentes do mercado da construção civil. Nos últimos anos, tem-se observado o crescimento do número de empreendimentos verticais que utilizam como diferencial de mercado a flexibilidade de layout arquitetônico.

Por conseguinte, como o próprio cliente tem liberdade de definir as dimensões de boa parte dos cômodos e, por isso, o comprimento de parede, o termo área útil passou a tomar outra importância.

$\mathrm{Na}$ verdade, uma vez que a área útil é, nesta nova concepção, algo variável segundo as determinações de cada comprador, ganha importância outra grandeza - a área utilizável.

Esta última representa a proporção da área total que pode ser aproveitada de forma direta como área útil ou para a passagem de paredes divisórias dos ambientes. Pode ser obtida pela diferença entre área total em planta e a área ocupada pela estrutura. 


\section{Cenários e pressupostos adotados}

São análogos ao do item anterior. Ademais, com o auxílio da empresa responsável pela execução da estrutura $\mathrm{C}$ realizou-se levantamento do preço de venda da área útil e da área utilizável. O preço da área útil, já descontando o gasto com acabamento, foi estimado em 1800 reais por metro quadrado. Já o preço da área utilizável, já descontando o gasto com acabamento da mesma, foi estimado em 1600 reais pro metro quadrado.

\section{Determinação dos orçamentos}

Salienta-se que na composição dos orçamentos entram despesas fixas com a manutenção do canteiro de obra e parte das despesas administrativas da empresa. O montante mensal despendido, de acordo com a empresa encarregada da execução, ficou em 20.000 reais por mês. Como a edificação
$\mathrm{NC}$ é executada em 4 meses menos tempo, a mesma tem um gasto total 80.000 reais inferior à edificação C.

\section{Considerações sobre os resultados}

O modelo adotado apresenta as mesmas falhas citadas no item 6.1, não sendo o mais adequado para esta análise. A pesar disso, mostra-se mais completo, pois considera a edificação como um todo e benefícios indiretos.

Sem o devido desconto da renda adicional, a edificação NC foi $0,3 \%$ mais cara que a edificação C. Caso a venda fosse realizada com base no ganho de área útil, a edificação $\mathrm{NC}$ se tornaria $0,2 \%$ mais barata que a edificação C.

Mais interessante ainda seria a venda com base na área utilizável onde a estrutura $\mathrm{NC}$ foi $1,1 \%$ mais econômica que a estrutura $\mathrm{C}$.

Tabela 6. Levantamento dos custos descontados das edificações

\begin{tabular}{|c|c|c|c|}
\hline & \multirow{2}{*}{$\begin{array}{c}\text { Estrutura } \\
\text { Convencional }\end{array}$} & \multicolumn{2}{|c|}{ Edificação Não Convencional } \\
\hline & & $\begin{array}{c}\text { Consideração Da } \\
\text { Área Útil }\end{array}$ & $\begin{array}{c}\text { Consideração Da } \\
\text { Área Utilizável }\end{array}$ \\
\hline Ganho de Área $\left(\mathrm{m}^{2}\right)$ & - & 17 & 65 \\
\hline $\begin{array}{l}\text { Preço por Área } \\
\quad\left(\text { Reais } / \mathrm{m}^{2}\right)\end{array}$ & - & 1.800 & 1.500 \\
\hline $\begin{array}{c}\text { Recebimento } \\
\text { Adicional (Reais) }\end{array}$ & - & 30.600 & 97.500 \\
\hline $\begin{array}{l}\text { Custo da Edificação } \\
\text { (Reais) }\end{array}$ & 6.970 .104 & 6.988 .002 & 6.988 .002 \\
\hline $\begin{array}{l}\text { Custo da Edificação } \\
\text { Descontada (Reais) }\end{array}$ & 6.970 .104 & 6.957 .402 & 6.890 .502 \\
\hline
\end{tabular}

A renda adicional teria melhores resultados, caso a edificação em estudo possuísse garagens. A existência apenas de pilares perimetrais na estrutura NC permitiria a reorganização e aumento no número de vagas disponíveis. Mesmo assim, só a consideração de alguns resultados indiretos e da edificação como um todo já causou grande diferença.

Na verdade, foram os benefícios indiretos que, em valores absolutos, pela primeira vez trouxeram o custo da edificação NC abaixo ao da edificação C. Com isso, altera-se completamente o resultado da análise apresentada no item 6.1 e, na mesma medida, espera-se ter respondido a questão sobre a relevância ou não da consideração de resultados indiretos.

Análise de viabilidade com base em indicadores econômicos e estudo de risco de investimento 


\section{Modelo adotado}

A partir dos cronogramas executivos obtidos anteriormente, fez-se o encadeamento dos gastos ao longo do tempo para cada edificação. Em seguida, realizou-se a determinação dos cenários de fundo para as análises.

Com a reunião das referidas informações, obteve-se o fluxo de caixa do empreendimento e, então, os indicadores econômicos a serem comparados.

A análise de risco advinda da mudança do sistema estrutural foi realizada mediante estudo dos resultados obtidos nos diversos cenários propostos. Tem-se este modelo de análise como o mais adequado para a determinação da real viabilidade dos empreendimentos.

Basicamente porque nele o processo decisório se baseia em indicadores econômicos verdadeiramente representativos. Em segunda instância, porque é o mais abrangente e que com melhor verossimilhança representa os diversos cenários e eventos de ocorrência passível.

Além disso, ele ainda permite a análise dos riscos pertinentes a cada opção de investimento e seu grande mérito reside em vincular a análise a diferentes realidades (cenários) mais detalhadas e com características probabilísticas.

\section{Cenários e pressupostos adotados}

Os pressupostos adotados são representados por cada cenário predefinido. Mesmo assim, algumas variáveis foram tomadas constantes.

As observações transcritas abaixo foram determinadas de acordo com as condições estabelecidas pela empresa responsável pela execução da edificação.

- O edifício é composto por 80 unidades habitacionais cada qual com área total de $164 \mathrm{~m}^{2}$ e área construída de $115 \mathrm{~m}^{2}$ aproximadamente.

- O preço médio de venda por unidade habitacional era de 185000 reais.
-Despesas legais, financeiras, com publicidade, de comercialização, com corretagem, com taxas e impostos de acordo com Heineck (2003) correspondem a aproximadamente $20 \%$ do preço da edificação.

- Por simplicidade, a consideração das referidas despesas fez-se pelo abatimento direto no preço de venda da unidade habitacional, que passou a ser contabilizado sob o valor efetivo de 155000 reais.

- A TMA estabelecida pela empresa responsável pela execução da estrutura $\mathrm{C}$ foi de $1,5 \%$ a.m..

- A condição de pagamento da unidade habitacional adquirida antes do término da execução fez-se por uma entrada de 20000 reais, além de parcelas mensais de 1000 reais, a partir da entrada até o mês de entrega do edifício.

- Entregue o edifício, os clientes que adquiriram unidades habitacionais antes desta data financiariam o restante a ser pago.

- Os clientes que adquirissem unidades habitacionais após a entrega do edifício financiaram omontante a ser pago integralmente. - No caso dos clientes que realizaram a compra antes da entrega do empreendimento, o repasse integral do montante restante por parte da entidade financiadora ocorreu um mês após aquela data.

- Para os clientes que realizaram a compra após a entrega do empreendimento, a contabilização da venda só foi feita após o repasse do montante integral por parte da entidade financiadora.

- Considerou-se que todo o investimento no empreendimento partiu de capital próprio da empresa.

Poder-se-ia ter optado, na última consideração, por simular o financiamento do montante investido. Sem dúvida os resultados seriam diferentes dos obtidos no presente estudo. Entretanto, como a análise se baseia no rendimento do capital investido, 
preferiu-se manter o fluxo de caixa puramente com investimentos próprios da empresa. Assim, ter-seia uma idéia exata da magnitude do rendimento proporcionado.

Ademais, caso se optasse por financiamento, mesmo que de parte do montante investido, tenhase em mente o pagamento de juros sobre o capital emprestado. Em vez disso, a análise tenderia a ser bem mais favorável ao empreendimento de prazo executivo mais curto, ou melhor, mais favorável à edificação NC.

Seguem os demais pormenores de cada um dos cenários considerados.

\section{- Cenário 0}

É o cenário com maior probabilidade de ocorrência. Adite ritmo de vendas constate de 2 unidades habitacionais por mês.

A data de início das vendas coincide com o início das obras para ambas as edificações. Portanto, o tempo total para a comercialização de todas as unidades foi de 40 meses.

\section{- Cenário 1}

Neste cenário, procurou-se determinar o máximo atraso possível no início das vendas do Cenário 0 para que a estrutura $\mathrm{NC}$ ainda mantivesse sua viabilidade perante a estrutura C. Admite-se ritmo de vendas de 2 unidades habitacionais por mês.

\section{- Cenário 2}

Este cenário procura levar em conta que com o término da execução da edificação, pelo próprio impacto visual do prédio, ocorre aumento no ritmo de vendas.

Admitem-se dois ritmos de vendas: o primeiro de uma unidade por mês e o segundo de duas unidades por mês.

A data de início das vendas coincide com o início das obras para ambas as edificações. $\mathrm{O}$ mês de mudança de ritmo de venda coincide com o término executivo da edificação C.

Note-se que a mudança de ritmo ocorreu no mesmo mês para as duas edificações estudadas $\left(30^{\circ}\right.$ mês). Trata-se, por isso, de uma condição extremamente desfavorável para a edificação NC, visto que esta já se encontrava concluída quatro meses antes.

\section{- Cenário 3}

Este cenário procura levar em conta que com o término da execução da edificação, pelo próprio impacto visual do prédio, ocorre aumento no ritmo de vendas.

Admite dois ritmos de vendas: o primeiro de uma unidade por mês e o segundo com duas unidades por mês. A data de início das vendas coincide com o início das obras para ambas as edificações.

Para a edificação C, o mês de mudança de ritmo de venda coincide com o término executivo da mesma ( $30^{\circ}$ mês). Para a edificação NC, o mês de mudança de ritmo de venda ocorre 3 meses após o término executivo da mesma ( $29^{\circ}$ mês). Trata-se, por isso, de uma condição extremamente desfavorável para a edificação NC visto que esta já se encontrava concluídos três meses antes do $29^{\circ}$ mês.

\section{- Cenário 4}

Idêntico ao cenário 4 salvo pela mudança de ritmo de vendas que para a estrutura NC ocorre 2 meses após o término de sua execução ( $28^{\circ}$ mês). Trata-se, por isso, de uma condição desfavorável para a edificação NC, visto que esta já se encontrava concluídos dois meses antes do $28^{\circ}$ mês.

\section{- Cenário 5}

Idêntico ao cenário 4. Entretanto, a mudança de ritmo de vendas para a estrutura NC ocorre 1 meses após o término de sua execução ( $27^{\circ}$ mês).

Ainda se trata de uma condição mais desfavorável para a edificação NC. 


\section{- Cenário 6}

Idêntico ao cenário 4. Entretanto a mudança de ritmo de vendas para a estrutura NC ocorre no mês do término de sua execução ( $26^{\circ}$ mês).

\section{- Cenário 7}

Dentre os cenários 2, 3, 4, 5, 6, considerou-se como de mais provável ocorrência o de número 5.

Para este, analogamente ao realizado no Cenário 2, procurou-se determinar o máximo atraso possível no início das vendas para que a estrutura $\mathrm{NC}$ ainda mantivesse sua viabilidade perante a estrutura $\mathrm{C}$.
Havia também simulações de cenários com atrasos nos ritmos construtivos de ambas as edificações. Porém, optou-se por não representálos no presente trabalho.

Observou-se que a diferença percentual entre os indicadores das edificações se mantinha praticamente constante e igual ao exposto abaixo independentemente do atraso executivo dado.

\section{Determinação dos indicadores econômicos}

Utilizando os cenários de 0 até 7 obteve-se a tabela abaixo referente aos indicadores econômicos.

Tabela 7. Comparativo dos indicadores econômicos de ambas as edificações

\begin{tabular}{|c|c|c|c|c|c|c|c|}
\hline & \multirow[t]{2}{*}{ Observação } & \multicolumn{2}{|c|}{$\begin{array}{l}\text { Edifícação Não } \\
\text { Conveiconal } \\
\text { Convencional }\end{array}$} & \multicolumn{2}{|c|}{$\begin{array}{l}\text { Edificação } \\
\text { Conveiconal } \\
\text { Convencional }\end{array}$} & \multirow{2}{*}{$\begin{array}{c}\text { Diferença } \\
\text { Percentual } \\
\text { (NC/C-1) } \\
\text { VPL } \\
\end{array}$} & \multirow{2}{*}{$\begin{array}{c}\text { Diferença } \\
\text { Absoluta } \\
\text { (NC-C) }\end{array}$} \\
\hline & & TIR & VPL* & TIR & VPL* & & \\
\hline $\begin{array}{c}\text { Cenário } \\
0\end{array}$ & Mais Provável & $3,36 \%$ & 2104324 & $3,24 \%$ & 1992896 & $5,59 \%$ & 111429 \\
\hline $\begin{array}{c}\text { Cenário } \\
1\end{array}$ & $\begin{array}{l}\text { Muito Pessimista - } \\
13 \text { meses de atraso } \\
\text { no primeiro } \\
\text { recebimento do } \\
\text { "Cenário 0" }\end{array}$ & $2,38 \%$ & 1321781 & $2,39 \%$ & 1313356 & $0,64 \%$ & 8424 \\
\hline $\begin{array}{c}\text { Cenário } \\
2\end{array}$ & $\begin{array}{c}\text { Muito Pessimista - } \\
4 \text { meses de atraso } \\
\text { na mudança de } \\
\text { ritmo de venda da } \\
\text { Edifc. NC }\end{array}$ & $2,27 \%$ & 1184745 & $2,30 \%$ & 1204553 & $-1,64 \%$ & -19808 \\
\hline $\begin{array}{c}\text { Cenário } \\
3\end{array}$ & $\begin{array}{c}\text { Pessimista - } 3 \\
\text { meses de atraso na } \\
\text { mudança de ritmo } \\
\text { de venda da Edifc. } \\
\text { NC }\end{array}$ & $2,29 \%$ & 1215109 & $2,30 \%$ & 1204553 & $0,88 \%$ & 10556 \\
\hline $\begin{array}{c}\text { Cenário } \\
4\end{array}$ & $\begin{array}{c}\text { Pessimista - } 2 \\
\text { meses de atraso na } \\
\text { mudança de ritmo } \\
\text { de venda da Edifc. } \\
\text { NC }\end{array}$ & $2,32 \%$ & 1246938 & $2,30 \%$ & 1204553 & $3,52 \%$ & 42385 \\
\hline $\begin{array}{c}\text { Cenário } \\
5\end{array}$ & $\begin{array}{c}\text { Provável - } 1 \text { mês } \\
\text { de atraso na } \\
\text { mudança de ritmo } \\
\text { de venda da Edifc. } \\
\text { NC } \\
\text { Provável - sem }\end{array}$ & $2,35 \%$ & 1279245 & $2,30 \%$ & 1204553 & $6,20 \%$ & 74692 \\
\hline $\begin{array}{c}\text { Cenário } \\
6\end{array}$ & $\begin{array}{l}\text { atraso na mudança } \\
\text { de ritmo de venda } \\
\text { da Edifc. NC }\end{array}$ & $2,38 \%$ & 1313061 & $2,30 \%$ & 1204553 & $9,01 \%$ & 108509 \\
\hline $\begin{array}{c}\text { Cenário } \\
7\end{array}$ & $\begin{array}{l}\text { Muito Pessimista - } \\
24 \text { meses de atraso } \\
\text { no primeiro } \\
\text { recebimento do } \\
\text { "Cenário 5" }\end{array}$ & $1,63 \%$ & 265109 & $1,63 \%$ & 261921 & $1,22 \%$ & 3187 \\
\hline \multicolumn{8}{|c|}{ Valores em reais } \\
\hline
\end{tabular}




\section{Considerações sobre os resultados}

Em todos os cenários estabelecidos - mesmos nos mais pessimistas, a TIR das edificações ficaram acima da TMA predeterminada. Um forte indício de viabilidade dos empreendimentos perante o mínimo de rentabilidade pretendido pelo investidor. Ademais, nos cenários "prováveis" e "mais provável", o rendimento esperado para a edificação $\mathrm{NC}$ foi maior que a $\mathrm{C}$. Isso, por si só, não significa que uma edificação é mais viável economicamente do que outra.

O parâmetro correto a ser comparado para obter tal resposta é o VPL. Assim, ao contrapormos os valores obtidos, apenas no Cenário 2 (muito pessimista) a estrutura $\mathrm{C}$ mostrou-se mais viável economicamente que a estrutura NC. Nos demais casos, sejam eles muito pessimistas, pessimistas, prováveis ou muito prováveis a edificação NC transpareceu mais viável economicamente.

Todavia, ainda paira sobre o assunto a questão: "Qual o risco implícito de optar-se em investir na estrutura $\mathrm{NC} \mathrm{e}$, por isso, obter resultados piores do que se escolhesse investir na estrutura C?".

Ora veja, dos cinco cenários qualificados como pessimistas ou muito pessimistas apenas um apontou resultado mais compensatório para a estrutura $\mathrm{C}$. Porém neste cenário, como nos de número 3 e 4 , de acordo com seus pressupostos, há um desfavorecimento elevado e concentrado unicamente na estrutura NC. Ainda assim, nos dois últimos, a estrutura NC apresentou VPL respectivamente $0,88 \%$ e $3,55 \%$ maior que a estrutura $\mathrm{C}$.

Vide também nos cenários 2 e 7, a grande magnitude dos atrasos limites dados ao início das vendas de ambas as edificações para que houvesse maior viabilidade da estrutura NC (respectivamente 13 e 24 meses).

Já nos cenários qualificados como prováveis ou muito prováveis, a estrutura NC mostrou larga vantagem tendo VPL no mínimo 5,6\% superior que o da estrutura C. Destaque ao Cenário 1 (muito provável) onde a diferença absoluta do VPL chegou a 111.429 reais. Apesar de não constar na tabela qualquer cenário qualificado como otimista, se por hipótese este ocorresse, os VPL obtidos dariam margem ainda mais sólida para a estrutura NC. Assim, resumindo o exposto acima em palavras mais simples: no presente estudo de caso, é muito pequena a probabilidade de optar-se pela estrutura NC e, por isso, "errar na escolha".

Para muitos, uma constatação cuja firmeza pode soar estranha. Principalmente ao avaliar-se o exposto até então.

Viu-se no item 5.2 alguns descontos em função do ganho da área útil ou utilizável os quais sequer foram excogitados aqui. Em parte por isso, a edificação NC exige um volume de investimento maior que o demandado para a edificação C. Para piorar, o menor prazo executivo da edificação NC implica em velocidade bem mais acelerada de aporte de capital para investimentos.

Tornam-se compreensíveis, portanto, os eventuais questionamentos iniciais sobre um resultado que desafia o racionalmente esperado.

São dois os principais fatores que explicam a resposta aparentemente estranha:

- A consideração do efeito do tempo inerente ao modelo empregado e;

- As características ordinariamente vigentes no financiamento das unidades habitacionais aos clientes.

Enquanto o cliente assume o financiamento de seu apartamento, geralmente a entidade financiadora repassa de imediato e integralmente ao fornecedor, o montante total financiado.

Para as aquisições que se dão antes da conclusão da obra, mesmo com o financiamento aprovado, o repasse só ocorre após àquela data. Assim, só quando findada a obra, o repasse do montante restante a ser pago é realizado pela entidade financiadora.Por questões legais, existe ainda um certo prazo entre a conclusão da obra e o repasse do montante - um mês para o presente estudo. 
Independentemente disso, visto que a edificação NC é concluída com 4 meses de antecedência, o repasse também ocorre antes.

Como os valores envolvidos no primeiro repasse são elevados, o retorno propiciado pelo recebimento antecipado tende a sobrepujar a questão dos maiores custo e velocidade de investimentos pertinente à edificação NC.

Portanto, fica explícito que a maior rentabilidade desta edificação está diretamente ligada ao aumento da velocidade executiva. Uma prerrogativa somente possível em função do sistema estrutural adotado.

\section{Conclusões}

Fica claro que os resultados de um estudo de viabilidade econômica são diretamente influenciados pelo modelo adotado. Tamanha é a diferença que, de um modelo para outro, passa-se de uma análise positiva para uma negativa. Mas em meio aos diversos resultados conflitantes e distintos qual servirá de base para o processo decisório?

Esta questão mais que uma dúvida vem expressar a necessidade em se conhecer a fundo a peculiaridade e propriedade de cada modelo de análise empregado. Por regra, é interessante optar pelo modelo mais abrangente, mais verossímil e de resultados mais representativos. Já o nível de detalhamento a ser dado dependerá do equilíbrio entre a praticidade, grau de importância e representatividade exigida do estudo. Para empreendimentos semelhantes ao presente estudo de caso, pelo grande montante envolvido e longo prazo de maturação sugere-se o modelo tipificado no item 6.3.

Segundo este estudo, foi possível demonstrar que, perante os diversos cenários apresentados, os indicadores econômicos apontam considerável e favoravelmente em direção à edificação NC.

Também por isso, são bem reduzidos os riscos implícitos em optar pela referia edificação e obter rendimento de capital investido inferior ao esperado em cenário análogo para a edificação $\mathrm{C}$.

Assim, mesmo exigindo maior investimento, das duas edificações estudadas, a NC, com boa margem de vantagem, tende a ser economicamente mais viável.

\section{Referências}

GALESNE, A.; FENSTERSEIFER, J. E.; LAMB, R.. Decisões de investimento da empresa. São Paulo: Atlas, 1999.

HEINECK, L. F. M. Notas de aula do curso de especialização em gerenciamento de obras. UFBA: Salvador, 2003.

ROCHA, S. Desempenho medido na prática. Revista Téchne, São Paulo, v.29, p.14-17,jul.-agos. 1997. 